\title{
Observatório
}

\section{HISTÓRIA DIGITAL, \\ SOCIOLOGIA DIGITAL E \\ HUMANIDADES \\ DIGITAIS: Algumas \\ questões \\ metodológicas}

DIGITAL HISTORY, DIGITAL SOCIOLOGY AND DIGITAL HUMANITIES: Some methodological questions

HISTORIA DIGITAL, SOCIOLOGÍA DIGITAL Y HUMANIDADES DIGITALES: Algunas cuestiones metodológicas

\section{Helyom VianaTelles ${ }^{1,2}$}

\section{RESUMO}

O artigo discute o conceito de Digital e a constituição do campo das Humanidades Digitais, destacando alguns problemas específicos inerentes à Sociologia, Antropologia e Historiografia. O artigo explicita a polêmica em torno do conceito de digital e pontua algumas questões metodológicas relevantes para a construção da objetividade científica no uso dos métodos digitais no campo da Historiografia e das Humanidades Digitais.

\footnotetext{
${ }^{1}$ Pós-Doutor em Educação e Contemporaneidade pela Uneb (2015) e Doutor em Ciências Sociais pela Universidade Federal da Bahia (2009). Coordenador do Núcleo de Antropologia Digital, História Oral e Visual-NAHV e Pesquisador vinculado ao Grupo Comunidades Virtuais (PPGEduC-UNEB). Pesquisador filiado às seguintes organizações: American Anthropological Association, American Historical Association, Asociación Antropólogos Iberoamericanos En Red, Associação Nacional de Professores Universitários de História (ANPUH) e Sociedade Brasileira de Teoria e História da Historiografia (SBTHH). Professor da Universidade Estácio de Sá. E-mail: helyom@gmail.com.

${ }^{2}$ Endereço de contato do autor (por correio): Universidade Federal da Bahia. Instituto de Humanidades, Artes e Ciências Professor Milton Santos - IHAC. Rua Barão de Jeremoabo, PAF IV - Sala 306 , s/n , Ondina , 40170-115, Salvador-Bahia, Brasil.
} 


\title{
Observatón \\ DOI: http://dx.doi.org/10.20873/uft.2447-4266.2017v3n5p74
}

PALAVRAS-CHAVES: História Digital, Humanidades Digitais, Sociologia Digital.

\begin{abstract}
The article discusses the concept of Digital and the constitution of the field of Digital Humanities, highlighting some specific problem sinherent in Sociology, Anthropology and Historiography. The article explores the controversy surrounding the concept of digital and points out some methodological issues relevantto the construction of scientific objectivity in the use of digital methods in the field of Historiography and Digital Humanities.
\end{abstract}

KEYWORDS: Digital History, Digital Humanities, Digital Sociology.

\section{RESUMEN}

El artículo discute el concepto de Digital y la constitución del campo de las Humanidades Digitales, destacando algunos problemas específicos inherentes a la Sociología, Antropología y Historiografía. El artículo explicita la polémica en torno al concepto de digital y puntualiza algunas cuestiones metodológicas relevantes para la construcción de la objetividad científica en el uso de los métodos digitales en el campo de la Historiografía y de las Humanidades Digitales.

PALABRAS CLAVES: Historia Digital, Humanidades Digitales, Sociología Digital.

Recebido em: 30.05.2017. Aceito em: 01.07.2017. Publicado em: 01.08.2017. 


\section{Obser \\ ISSN n² 2447-4266 \\ Vol. 3, n. 4, Agosto. 2017 \\ DOI: http://dx.doi.org/10.20873/uft.2447-4266.2017v3n5p74}

\section{Introdução}

Por volta do ano de 2012, me interessei em ampliar as discussões sobre memória coletiva, reposicionando-a em relação às investigações sobre as tecnologias da comunicação e informação. O resultado foi uma pesquisa de Pós-Doutorado desenvolvida junto à Pós-Graduação em Educação e Contemporaneidade da UNEB sobre Jogos Digitais, História e Memória Coletiva. Mais recentemente, os resultados obtidos por esse projeto me conduziram às discussões sobre História Pública Digital, Metodologias Informacionais e Humanidades Digitais. Fiquei particularmente interessado nas possibilidades de utilização de programas como o N-Vivo na pesquisa social. No presente artigo, apresento uma discussão introdutória ao tema das Humanidades Digitais, a partir de contribuições da Antropologia, Sociologia e História Digital. Inicialmente, discuto o conceito de digital. Mais adiante, tento esboçar alguns dos elementos que constituem o campo de pesquisa da Antropologia, Sociologia e História Digital. Não poderia ser de outro modo, uma vez que, em função da minha formação acadêmica tanto no campo da Historiografia e das Ciências Sociais, tenho procurado sistematicamente promover um diálogo constate entre esses campos disciplinares. Por fim, apresento uma discussão metodológica com questionamentos de ordem metodológica que são específicos do campo historiográfico e outros que são comuns ao campo das Humanidades Digitais e que desse modo se mostram também relevantes para os historiadores. 


\section{Obser \\ ISSN n² 2447-4266 \\ Vol. 3, n. 4, Agosto. 2017 \\ DOI: http://dx.doi.org/10.20873/uft.2447-4266.2017v3n5p74}

\section{Sobre o conceito de digital}

De acordo com Segata (2014), as pesquisas sobre cultura e tecnologia digital no campo da Antropologia ao longo dos anos 1990 foram inicialmente lastreadas pelo conceito controverso de cibercultura. Essa etapa foi marcada pela aproximação com o campo da comunicação social e pela hipótese de que os computadores e a internet reconfiguraram as formas de expressão da sensibilidade e do conhecimento. $O$ interesse recaia basicamente sobre o compartilhamento de informações através do uso dos e-mails, blogs, os jogos e por fim, as redes sociais.

Para Máximo (2010) o contexto das interações mediadas por computador e os estudos sobre o ciberespaço contribuiriam para a problematização de questões teóricas e metodológicas da Antropologia no sentido de rever interpretações habitualmente concedidas às interações face a face. De outro lado, o trabalho etnográfico sobre o ciberespaço revelou que a interação mediada por computador é pautada em padrões culturais, sendo necessário entender as especificidades de cada grupo e contexto cultural para a correta interpretação dessas interações. A autora sustenta que um traço distintivo da contemporaneidade é a substituição de fronteiras espacialmente delimitadas por sentimentos de pertencimento a grupos com regras e éticas específicas, tendo como suporte a produtividade social no ciberespaço e a expansão da rede de computadores. Uma vez que ela permite coordenar atividades sociais sem a mediação do lugar, as relações sociais se deslocaram dos contextos locais. Nessa perspectiva, o ciberespaço aparece como um elemento que pode ser pensado como um 


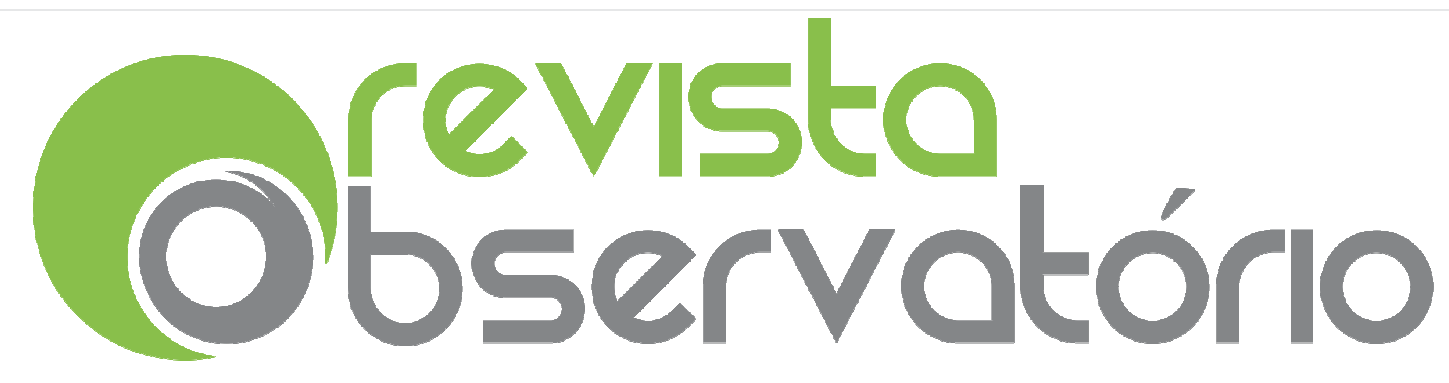

ISSN n² 2447-4266

Vol. 3, n. 4, Agosto. 2017

DOI: http://dx.doi.org/10.20873/uft.2447-4266.2017v3n5p74

"espaço urbano que contribui para formação da espacialidade das grandes cidades, pontuada por redes decomunicação" (Maximo, 2010, p.40)

Segata (2014) sublinha que as controvérsias inerentes ao período confrontavam posições entusiastas e pessimistas sobre as tecnologias. Entretanto apesar do diálogo estabelecido com o campo da Comunicação ter sido produtivo, os antropólogos tinham mais interesse em problematizar os espaços de relacionamento do que os canais de comunicação propriamente ditos de modo trazer as relações entre as pessoas para o primeiro plano. No período, a noção de virtualidade estava bastante difundida e era compreendida como uma dimensão subjacente ao real. Muitos antropólogos tinham dificuldade em perceber o humano em meio ao tecnológico e, em função disso, cultivavam uma certa desconfiança em relação à possibilidade de uma pesquisa etnográfica desses fenômenos. Nesse contexto, a assunção de uma netnografia terminava por reforçar a dicotomia entre o real e o virtual. Em função desse impasse, alguns pesquisadores começaram a recorrer à noção de rede.

A questão crítica aqui é que rede, no sentido latouriano, é contingente, performática, não ontológica - não serve como objeto a ser descrito, senão apenas nos fornece algumas pistas metodológicas para o trabalho de descrição. Vínhamos adotando aquela de rede sociotécnica. Isso nos permitia, entre outras coisas, argumentar que on-linee off-line eram apenas distinções didáticas. Isso tudo, sem contar que o próprio ciberespaço é uma ideia desgraçada, que, vira e mexe, nos faz pensar num lugar especial da realidade, com propriedades especiais de explicação sobre o que entra e o que sai dele. E aí aparecem as novas formas de 


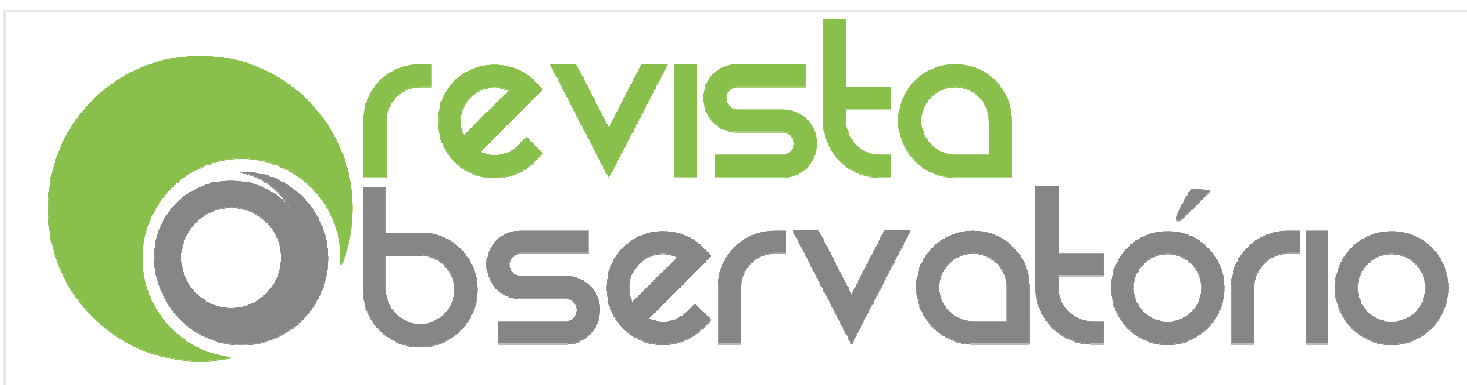

ISSN n² 2447-4266

Vol. 3, n. 4, Agosto. 2017

DOI: http://dx.doi.org/10.20873/uft.2447-4266.2017v3n5p74

comunicação, novas comunidades, novasidentidades, até uma cultura nova - a Cibercultura. Assim, como já mencionado, não era de se estranhar que frequentemente a ideia de "novas relações" era acionada nos discursos da cibercultura, pois se referiam de vínculos estabelecidos entre pessoas, a partir de novos ambientes técnicos que permitiam a conexão por meio de uma rede. Ainda sobre esse aspecto, foi preciso reconsiderar a natureza da ação, pois, seguindo, ainda, Latour (2012), o ator não é uma peça que já está no tabuleiro e que depois age. Ele não se refere exclusivamente aos humanos, mas a um ente que se constitui apenas na ação. Ele não existe como repertório, de modo que chega a ser redundante a afirmação de "atores em ação" - sua sugestão é a de que fujamos da ideia de que atores (ou actantes/atuantes) estão esperando em algum lugar, prontos e definidos, a hora de entrar em cena. Assim, a ação é pensada como um evento e não como um ato - localizando sujeitos e objetos. (Segata, 2014.p.80)

A diluição da oposição entre digital e não-digital também é a tônica da abordagem de Miller e Horst (2015). Os autores propõem uma definição dialética do digital, esse entendido como aquilo que pode ser reduzido a um código binário. A natureza dialética situase na relação entre universalidade e particularidade e seus efeitos positivos e negativos. A argumentação proposta pelos autores define seis princípios para a antropologia digital. O primeiro é a intensificação da natureza dialética da cultura pelo digital. O segundo é crítica a uma concepção romântica da vida pré-digital e a afirmação de que as possibilidades de mediação não foram ampliadas pelo digital. O terceiro princípio é reafirmação da posição holística da Antropologia. O quarto é a perspectiva da apreensão da diversidade cultural no digital. O quinto sublinha a ambiguidade da cultura digital e o último sustenta que os mundos 


\section{Observet}

ISSN n² 2447-4266

Vol. 3, n. 4, Agosto. 2017

DOI: http://dx.doi.org/10.20873/uft.2447-4266.2017v3n5p74

digitais são parte da materialidade da vida humana e, mais precisamente, são constituintes da vida humana.

Evitando a oposição entre analógico e digital, Miller e Horst (2015) definem o digital como aquilo que pode ser reduzido a um código binário. Sustentam que a codificação binária simplificou consideravelmente os processos de comunicação produzindo convergências entre conteúdos e tecnologias que antes eram díspares. A codificação binária possui um precedente histórico que é a utilização do sistema decimal para as trocas comerciais. Essa argumentação tem duas implicações. A primeira é que tanto o dinheiro como o digital podem ser entendidos como formas de abstração da vida humana. A segunda é que, tanto no sistema binário, como no sistema decimal, está em jogo uma redução das coisas que, ao ser levada adiante produzas diferenças. Está presente uma relação dialética entre o universal e o particular. É graças às propriedades virtuais do dinheiro que ele pode ser trocado de modo tão eficiente. No que diz respeito aos usos do digital, os autores sustentam que é a cultura que oferece o contexto e a significação. É preciso partir da compreensão da cultura local para entender os diferentes usos das tecnologias digitais.

É o uso da analogia com o dinheiro que permite a Miller e Horst (2015) criticar a noção de mediação. Para eles a ideia que o mundo pré-digital era "mais autêntico" e, portanto, menos mediado que o mundo digital não é sustentável. Ou seja, essa é uma percepção ilusória desses processos, pois nenhum deles escapa da 


\section{Obser \\ ISSN n² 2447-4266 \\ Vol. 3, n. 4, Agosto. 2017 \\ DOI: http://dx.doi.org/10.20873/uft.2447-4266.2017v3n5p74}

natureza mediadora da cultura. O digital é uma produção cultural e como tal, é parte integrante da experiência humana

\section{Sociologia, Historiografia e Humanidades Digitais}

A ideia da mediação é, entretanto, a base da tese de Lupton (2015). A autora defende que vivemos em uma sociedade digital na qual trabalho, lazer e relacionamentos são mediados por empresas de software de comunicação. Nesse contexto, os softwares e hardwares passam a ser elementos integrantes dos processos de vida social e da identidade. A larga difusão da tecnologia digital, sua pervasividade e ubiquidade atravessam as instituições comerciais, organizações, a política, o consumo e o gerenciamento das cidades. Portanto, apreensão da sociedade e da cultura passa pela compreensão da interação digital, o que implica dizer que a pesquisa sobre o digital se impõe como pauta para as Ciências Sociais, uma vez que todos os tópicos hoje estudados pela sociologia encontram-se inevitavelmente conectados com as tecnologias digitais.

O campo conhecido como sociologia digital além das discussões sobre o uso do digital pelos sociólogos (mídias sociais e tecnologias digitais) engloba também a discussão sobre a pratica e - futuro da sociologia e seus métodos, a pesquisa sobre as instituições digitais e a análise de dados digitais. A autora explica que a opção pelo uso do termo digital em lugar de noções como tecnologias da comunicação ou cibertecnologias é tendência 


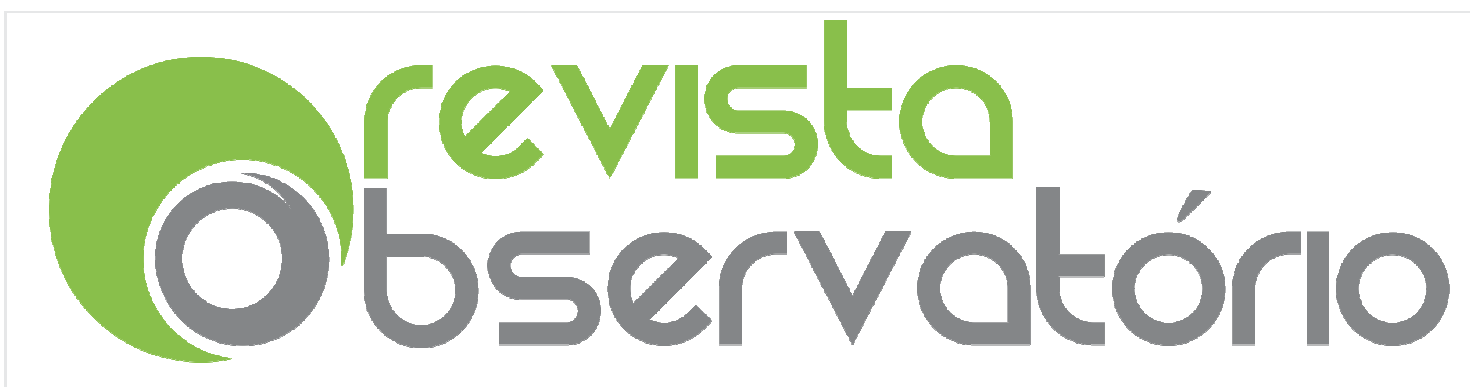

ISSN n² 2447-4266

Vol. 3, n. 4, Agosto. 2017

DOI: http://dx.doi.org/10.20873/uft.2447-4266.2017v3n5p74

recente entre as humanidades, a exemplo do campo das humanidades digitais. Ela utiliza o termo em contraste para as formas analógicas de gravação e transmissão. Ele se refere tanto ao software, quanto ao hardware e engloba também a tecnologia que os suporta. O digital também é entendido como produto da ação humana. É a partir das decisões humanas que o digital é produzido. Essa compreensão é extensiva aos dados digitais, esses entendidos como os objetos que passaram por um processo de codificação e transmissão digital. A facilidade com que as tecnologias digitais trocam dados umas com as outras faz deles um objeto de interesse para a sociologia. A atenção de Lupton se volta para a problematização da construção e do uso dos algoritmos, para a sua dimensão política e cultural.

Dados digitalizados relacionados às nossas interações rotineiras na internet incluindo pesquisas em motores de busca, chamadas, compras, agencias de governo e interações bancárias são coletadas automaticamente e arquivadas, produzindo conjunto de massas de dados agora conhecidos como big data. O big data também se referem ao conteúdo gerado pelo usuário, a informação intencionalmente carregada para plataformas de mídias sociais como parte de sua participação nesses sites; tweets, atualização de status, vídeos, fotografias, comentários, etc, o que édito, o perfil do falante sua audiência, como reagiram ao seu comentário. O valor da big data para fins comerciais e não comerciais tem aumentado, levantando questões sobre como tem sido utilizado e suas implicações para privacidade, segurança, política, vigilância, desenvolvimento global e economia. (Lupton, 2015, p.7) 


\section{Obser \\ ISSN n² 2447-4266 \\ Vol. 3, n. 4, Agosto. 2017 \\ DOI: http://dx.doi.org/10.20873/uft.2447-4266.2017v3n5p74}

As Humanidades Digitais podem ser pensadas como um campo interdisciplinar de conhecimento interessado na reflexão sobre produção, apropriação e usos das tecnologias digitais na academia. Esse campo se consolidou inicialmente no mundo anglosaxônico. Para além da discussão relacionada à incorporação e ao uso da tecnologia, há reflexões teóricas e epistemológicas próprias. É bem comum encontrar a proposição de projetos de pesquisa-ação e parcerias com movimentos sociais por parte de pesquisadores da área. É possível encontrar projetos que associem linguística, computação e matemática, historiografia e bancos de dados digitais. Muitos deles não utilizam a expressão "Humanidades Digitais". Para além da produção do conhecimento, há também a preocupação com o acesso e a difusão do conhecimento através das plataformas digitais. Metodologicamente há a questão central que norteia a pesquisa no campo, a saber, é a articulação dos conhecimentos das ciências humanas com o mundo digital (Almeida, 2015).

Em outras palavras isso implica na mudança da concepção sobre a própria pesquisa, que passa a ser pautada em uma estrutura cibernética que implica, para além da armazenagem, o uso de redes sociais e outras plataformas de modo a que os resultados dos projetos possam atingir a um público mais amplo. A multiplicação das interações tem um impacto considerável sobre o texto acadêmico, que passa a incorporar um valor relacional resultante de perspectivas diversas aproximando-se de um modelo de tipo rizomático, ou seja, um sistema aberto, não hierarquizado e sem centro. O próprio pesquisador precisa reposicionar-se diante 


\section{Obser \\ ISSN n² 2447-4266 \\ Vol. 3, n. 4, Agosto. 2017 \\ DOI: http://dx.doi.org/10.20873/uft.2447-4266.2017v3n5p74}

de um campo acadêmico que se mostra cada vez mais colaborativo e aprender a lidar com outras instâncias de legitimação cultural e avaliação de sua produção que envolvem agora "pares" que se encontram fora do mundo acadêmico (Pereira, 2015, p.12).

Zaagsmabmgn (2013) afirma que a noção de Humanidades Digitais evoca o novo e o inexplorado. A História ou Historiografia Digital consiste, primeiramente, em uma reflexão sobre a digitalização de documentos, arquivos e imagens no trabalho do historiador. Mas a História Digital também se refere à reflexão sobre as possibilidades do uso das redes sociais para comunicar conhecimentos históricos e ao uso do computador na pesquisa histórica.

Para Danniau (2013) isso significa ampliar os recursos de que a História Pública pode lançar mão para atingir seus objetivos de difundir o conhecimento histórico para um público mais amplo. Segundo Zaagsmabmgn (2013) o ano de 1963 foi o marco inicial do uso de computadores na pesquisa histórica com a publicação do trabalho de Roberto Busa sobre as obras de São Tomás de Aquino. É possível pensar em várias fases na periodização do uso de computadores na pesquisa histórica. São considerados marcos relevantes os impactos da difusão da computação nos anos 1980 e a criação da rede mundial de computadores no início da década de 1990. A partir daí teve início um trabalho crescente de construção de bases de dados históricos digitalizados aliado à institucionalização da comunicação e da discussão acadêmica online, particularmente na forma de e-mails e intercâmbios através de listas de discussão. Esses processos de desenvolveram 


\section{Obser \\ ISSN n² 2447-4266 \\ Vol. 3, n. 4, Agosto. 2017 \\ DOI: http://dx.doi.org/10.20873/uft.2447-4266.2017v3n5p74}

rapidamente em função do crescimento da digitalização no setor do patrimônio. Igualmente importante foi a rápida disseminação de novas formas de publicações e colaborações on-line, a exemplo dos blogs pessoais.

Zaagsmabmgn (2013) pontua que o interesse em métodos quantitativos de análise computadorizados teve início nos anos 1960,nos Estados Unidos, sob a influência da Nova História Econômica, como uma continuação lógica dos anos 1940 que usava cartões de perfuração. Esses estudos atingiram um ápice nos anos 1970, mas, no final dos anos 1980, declinaram em função da crise das abordagens quantitativas e da ascensão da vertente centrada na narrativa histórica. Já a Europa contou com um desenvolvimento bastante diversificado. Não foi observada uma influência significativa da Escola dos Annales na introdução da computação na historiografia francesa. O desenvolvimento da história quantitativa nos Estados Unidos foi consideravelmente mais avançada que na França, onde a influência dos historiadores da revista Le Médiéviste et l'Ordinateur, publicada no final dos anos 1970, foi mais relevante. De um modo geral o interesse pela computação entre os historiadores na Europa foi impulsionado pela criação da Associação para a História e Computação em 1987. Na Holanda, no final dos anos 1980 várias universidades organizaram departamentos voltados para oferecer a estudantes de ciências humanas treinamento no uso de computadores. Em 1988, foi criada a Comissão Belga-Holandesa para História e Computação. Entre 1988 e 1989 foi criado o Arquivo de Dados Histórico Holandês. 


\section{Obser \\ ISSN n² 2447-4266 \\ Vol. 3, n. 4, Agosto. 2017 \\ DOI: http://dx.doi.org/10.20873/uft.2447-4266.2017v3n5p74}

Para Pereira (2015) é equivocado reduzir as Humanidades Digitais à discussão sobre a utilização de ferramentas da informática á linguística, literatura e filologia, uma vez que isso teve lugar décadas atrás. Ele critica o uso indiscriminado da expressão História Digital para designar iniciativas generalistas referentes ao uso das tecnologias digitais nas Ciências Humanas. As Humanidades Digitais estão mais relacionadas à reinvenção da universidade e do seu papel na sociedade contemporânea.

\section{História Digital e Epistemologia da História}

Para Zahavi (2014), a partir dos anos 1980, o desenvolvimento tecnológico levou ao remodelamento das práticas historiográficas tradicionais à ampliação das possibilidades de divulgação das pesquisas historiográficas que passaram a contar com a possibilidade de produzir e compartilhar narrativas textuais em formas digitais. Além disso o próprio modo como o conhecimento histórico é coletado, preservado e disseminado foi modificado. Porém, do ponto de vista epistemológico, a História Digital pode ser incluída do rol das mudanças que tiveram lugar no campo historiográfico após a Segunda guerra Mundial. A exemplo, da História Oral e da História Social Quantitativa, que questionaram a primazia do trabalho escrito e o foco na elite; de modo semelhante à História Pública, que desafiou a centralidade do papel conferido ao historiador profissional; do mesmo modo que o pósmodernismo, que minou a autoridade conferidas às categorias produzidas pelos historiadores, a História Digital contribuiu para 


\section{Observe}

ISSN n² 2447-4266

Vol. 3, n. 4, Agosto. 2017

DOI: http://dx.doi.org/10.20873/uft.2447-4266.2017v3n5p74

problematização da compreensão dos historiadores sobre a pesquisa acadêmica. Dentre as oportunidades abertas pela História Digital está a criação de novas oportunidades e desafios a exemplo da capacidade de exibir fontes primárias e objetos de dados relacionados vinculados a essas fontes como tabelas, gráficos e mapas e a disseminação de plataformas de publicação. No campo das práticas, a História Digital também poderia contribuir para ensinar erudição histórica para os alunos de graduação, e melhorar a qualidade do ensino de história nas escolas primárias e secundárias. E isso pode ocorrer por que além de oferecer novas ferramentas para apresentar artefatos e eventos, também é possível tornar acessível e compreensível o processo de construção do argumento histórico (Dorn, 2013).

Para Tanaka (2013), a mídia eletrônica tem modificado não apenas a nossa relação com o passado, ela afeta também a nossa relação com o futuro. No entanto, a compreensão da natureza dessas mudanças não é simples. Ela exige que questionemos como a nossa própria compreensão da distinção entre passado e presente foi construída. Ele aponta que a modernidade naturalizou uma concepção de um modo cronológico de apreensão do passado e afirma que a institucionalização do pensamento historiográfico como um elemento central desse processo. Porém essa institucionalização não foi inócua. A adoção de um tipo de pensamento histórico baseado no encadeamento dos fatos em narrativas lineares, tal como proposto por Leopold von Ranke, consistiu na aniquilação de um passado prático e ético, da História magistral vitae, ou seja, um passado experimentado como um 


\section{Observalister \\ ISSN n² 2447-4266 \\ Vol. 3, n. 4, Agosto. 2017 \\ DOI: http://dx.doi.org/10.20873/uft.2447-4266.2017v3n5p74}

repositório de ideais e reflexões que julgavam o passado e orientavam e instruíam a vida no presente. Para Ranke a função da História deveria ser unicamente o relato preciso dos fatos. Desse modo, é no início do século XIX, que se emergiu uma nova forma de pensamento histórico, que separava o passado do presente, bem como uma escrita sobre o passado que se valia de uma estrutura linear, incorporando a noção newtoniana do tempo, em franco processo de universalização naquele período, e fundindo a cronologia com o tempo. Como consequência, a História passou a ser uma técnica de descrição de fatos. Contudo, esse novo passado, o passado histórico mostra-se desinteressado do cotidiano das atividades humanas, das emoções e da cultura. Ele está ocupado apenas com o que é datado, registrado e verificável e, portanto, daquilo que é descontextualizado.

Tanaka (2013) afirma que essa forma de pensamento histórico forneceu um instrumental importante para lidar com a comunidade de Estados-Nação que emergiu no século XIX, fornecendo um patamar normativo para lidar com a expansão econômica e política da Europa. Num momento em que a escrita da própria história era tarefa primordial para as nações, o papel do historiador profissional se consolidou e contribuiu para o esquecimento do processo que reduziu o passado a esse conjunto de narrativas cronológicas do Estado-nação. Num contexto em que predominava a noção de informação escassa em um mundo em rápida expansão, cabia ao historiador a coleta, categorização e disseminação da informação. No entanto, nos dias atuais, a mídia digital não funciona mais sob a condição de escassez de informações. Ao 


\section{Observe}

ISSN n² 2447-4266
Vol. 3, n. 4, Agosto. 2017

DOI: http://dx.doi.org/10.20873/uft.2447-4266.2017v3n5p74

contrário, temos um novo contexto de rápida proliferação de dados, facilidade de acesso e variados meios de interpretação. Essa mesma profusão de dados determina que o hábito de produzir um rápido constante esquecimento de informações desatualizadas, pode ser mais importante para o sucesso que a memorização de fatos passados. Em lugar de tornar a História ultrapassada, esse novo contexto modifica o modo com valorizamos, construímos e usamos passados e narrativas. Uma das importantes contribuições das tecnologias digitais consiste exatamente nisto, elas oferecem a possibilidade de conectar dados, representar o passado e evidenciar as particularidades de formas sociais herdadas, contribuindo para que os historiadores reconheçam a existência de outras formas de organização sócio temporais e trazendo a perspectiva de que a compreensão não está na acumulação de dados, mas no plano da construção de relações e conexões. Essa posição pode contribuir para repensar a prática e o valor da História para a sociedade contemporânea, além de recuperar a dimensão ética do conhecimento histórico.

Para Tanaka (2013) uma segunda contribuição das tecnologias digitais para o conhecimento histórico estaria na reconfiguração da nossa compreensão da mudança. Trata-se do abandono de uma métrica tecnológica e produtivista na qual o novo é melhor que o antigo, e da adoção de um ponto de vista do qual as ambiguidades e conflitos de narrativas sobre o passado passariam a ser considerados. Um evento histórico passaria a ser encarado como um plano de referência para inúmeras narrativas contadas sobre ele. 


\section{Observe}

ISSN n² 2447-4266
Vol. 3, n. 4, Agosto. 2017

DOI: http://dx.doi.org/10.20873/uft.2447-4266.2017v3n5p74

\section{Problematizando o uso dos dados e algoritmos}

Gibbs e Owens (2013) identificaram um paradoxo na relação entre o trabalho do historiador $e$ as fontes digitais. Se o crescimento vertiginoso da oferta de fontes e documentos digitais traz inúmeras facilidades de acesso a inúmeros materiais de pesquisa, os métodos para interagir com os dados, em sua maioria ainda se mantêm presos a convenções tradicionais. Isso é um grande problema, uma vez que o domínio da erudição histórica parece ser cada vez mais dependente do uso de algoritmos de busca cuja lógica permanece, em sua maioria, obscura para os pesquisadores. Definindo "dados" como as informações processáveis por computador, Gibbs e Owens (2013) alertam para o cuidado de confundir dados e evidências, ainda que os dados possam, em alguma circunstância específica, serem utilizados como evidência para algum argumento histórico. Trocando em miúdos, os dados são o resultado de um processo de obtenção de dados. Não são uma representação direta do registro histórico, mas resultam do uso de ferramentas específicas para a sua obtenção.

Também é preciso refletir sobre o problema da especificidade do uso dos dados para o campo historiográfico. Apesar de ser possível fazer uso de métodos estatísticos complexos para produzir conhecimento, Gibbs e Owens (2013), argumentam que, ao contrário do campo das Ciências Sociais, na História, o rigor matemático não é essencial para um uso eficaz dos dados, que poderiam ser abordados, por exemplo, de modo exploratório. A mesma lógica pode ser aplicada para a situação de interpretação 


\section{Obser \\ ISSN n² 2447-4266 \\ Vol. 3, n. 4, Agosto. 2017 \\ DOI: http://dx.doi.org/10.20873/uft.2447-4266.2017v3n5p74}

de dados para fins de testes de hipóteses. Em História, para além do problema da evidência, os dados podem ser utilizados para descobrir ou orientar novas questões de pesquisa, sobretudo quando visualizados de forma gráfica ou manipulados através de interações. A própria estética resultante deles pode ser a base de novos conhecimentos. Outro aspecto a ser ressaltado é que, com o aumento da facilidade de obtenção e manipulação dos dados, a própria dinâmica da pesquisa histórica poderia vir ser modificada passando a contar com uma fase inicial de exploração desses dados. Além disso, o uso de grandes bancos de dados a exemplo dos Arquivos Nacionais pode favorecer a adoção de metodologias não-lineares permitindo, por exemplo, a participação de outros pesquisadores no processo de investigação. A publicização do desenho metodológico da pesquisa pode ser útil para o ensino das práticas de pesquisa histórica. Esse é um aspecto importante.

Gibbs e Owens (2013) defendem que a utilização de novos métodos para explorar e interpretar dados históricos exige a adoção de um novo padrão de transparência metodológica na escrita da História, de modo que as publicações explicitem a hermenêutica dos dados digitais utilizada, ou seja, os processos de produção de sentido construídos a partir da exploração e interação com os dados utilizados. Como consequência, isso significaria a atribuição de um peso menor à narrativa e uma ênfase à argumentação e aos dados utilizados para apoiá-la.

Retornemos à discussão proposta por Lupton (2015). A preocupação da autora com a construção e o uso dos algoritmos é pertinente. O uso dos algoritmos está na base de um campo de 


\section{Obser \\ ISSN n² 2447-4266 \\ Vol. 3, n. 4, Agosto. 2017 \\ DOI: http://dx.doi.org/10.20873/uft.2447-4266.2017v3n5p74}

estudos produzido a partir da expansão, o uso e o consumo de imensas bases de dados. Berry e Linofd (1997) definem a mineração de dados como a exploração de análise de grandes quantidades dedados com o objetivo de identificar regras e padrõespara subsidiar futuras tomadas de decisões. Para isso são utilizados métodos e ferramentas de diferentes áreas como Estatística, visualização de dados e banco de dados. Para Goebel e Gruenwald (1999) a mineração de dados é parte do processo de Descoberta de Conhecimento em Banco de Dados ou KDD(Knowledge Discovery in Databases). Enquanto campo de conhecimento, O KDD representa um esforço amplo e sistemático no sentido de produzir ferramentas de pesquisa de conhecimento em grandes bases de dados (Fayyad et al., 1996). A mineração de dados representa o centro desse processo. Aqui determinados algoritmos são usados para obter resultados específicos. Em um ciclo completo de KDD são utilizados diferentes tipos de algoritmos para distintas finalidades.

Para Conte et al. (2013) o trabalho com a enorme massa de dados sobre a vida cotidiana gerada pelas tecnologias digitais permite apreender a complexidade de uma sociedade global caracterizada por um rápida transformação e fenômenos como epidemias, crises e conflitos étnicos e religiosos. Desse modo, a sociologia não pode se furtar à tarefa de apreendê-los e interpretá-los:

A análise de grandes conjuntos de dados, obtidos, por exemplo, a partir de chamadas de telefonia móvel, redes sociais, ou atividades comerciais fornece insights sobre fenômenos e processos ao nível das relações sociais. Investigações sobre as 'pegadas eletrônicas' deixadas pelas pessoas já contribuem para o entendimento da 


\section{Observ}

ISSN n² 2447-4266
Vol. 3, n. 4, Agosto. 2017

DOI: http://dx.doi.org/10.20873/uft.2447-4266.2017v3n5p74

relação entre a estrutura da sociedade e a intensidade das relações sociais". (Conte et al., 2013.p.24).

Caberia à Ciência Social computacional a investigação desses imensos bancos de dados. Trata-se de um campo interdisciplinar com o qual cooperam sociólogos, matemáticos, cientistas da computação. A ideia é modelar e simular processos sociais em larga escala de modo a obter a compreensão das suas interdependências. Os resultados poderão ser utilizados em processos de formulação e avaliação de políticas públicas, uma vez que as simulações poderão ser compartilhadas publicamente. $O$ desenvolvimento da ciência social computacional só será possível com o desenvolvimento de uma teoria própria e testagem através de experimentos de larga escala. Para isso se faz necessário a cooperação com os cientistas da computação.

Para Pereira (2015) recursos como a mineração e a visualização de dados são respostas ao extraordinário aumento na produção e circulação de informação no campo das humanidades consistido em um tipo de leitura computacional ou leitura assistida por computador que vem ganhando cada vez mais uso e legitimidade na academia. Trata-se de uma mudança radical no modo como os pesquisadores das humanidades lidam com os textos, passando da análise minuciosa de um único texto ao processamento de enormes conjuntos de dados originados a partir da digitalização de modo a extrair deles um padrão.As técnicas de Big Data também passaram a ser utilizadas no campo do ensino em rede (Educational Data Miningou Learning Analytics) com o objetivo de oferecer um acompanhamento mais direto do processo 


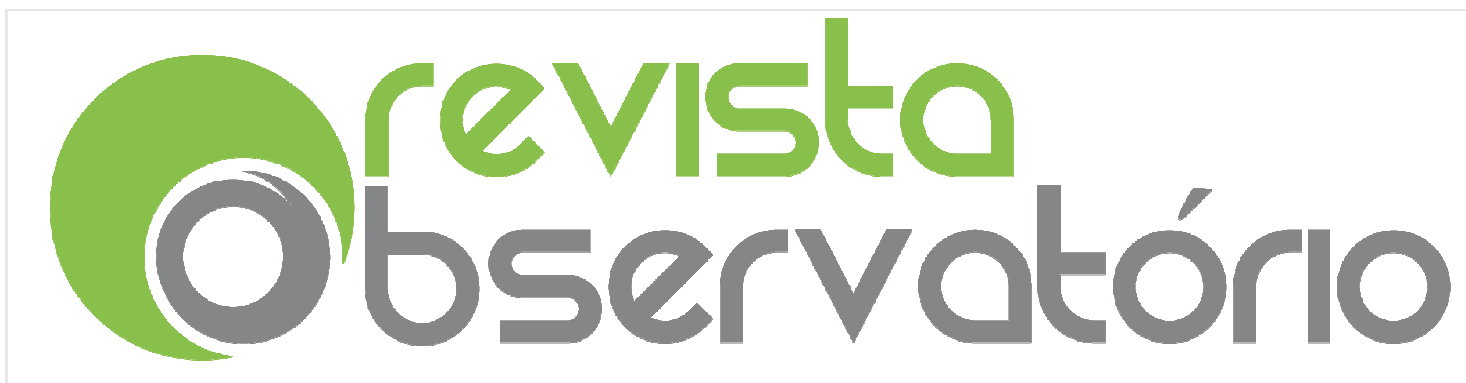

ISSN n² 2447-4266

Vol. 3, n. 4, Agosto. 2017

DOI: http://dx.doi.org/10.20873/uft.2447-4266.2017v3n5p74

do estudante. As consequências desse "giro digital" (Noiret, 2015) é um alargamento tão significativo da compreensão sobre os fenômenos culturais, que é possível sustentar a existência de um giro paradigmático:

\begin{abstract}
Nesse sentido, a expansão do fenômeno Big Data não pode ser desligada de uma outra tendência forte das últimas décadas como é o Open Data, no sentido de livre disponibilização de dados online, sem os constrangimentos legais típicos do copyright e com uma natureza técnica que permite e elevados níveis de utilização e de circulação de dados [36]. Tendo em conta a complexidade crescente de tal estrutura formada por bases de dados interconectados e abertos, de acesso público, estamos a caminhar cada vez mais no sentido de um paradigma que tem sido designado por alguns como Big-Linked-OpenData, com notáveis implicações sobre vários setores da atividade humana, incluindo o campo das Humanidades, nomeadamente a nível de protocolos de pesquisa e do surgimento de plataformas ou ferramentas Open Source em rede que permitem a recolha, análise e visualização de forma síncrona dos dados"(Pereira, 2015, p.9).
\end{abstract}

Indagando sobre a importância dos Big Data para a historiografia Baerman (2015) observa que o rápido processo de digitalização em larga escala de dados e arquivos históricos cria novos repositórios culturais que permitem compreender fenômenos importantes como formação e integração de grupos étnicos. Essa nova estrutura de dados pode mudar radicalmente o modo como os historiadores imaginam o passado e promover uma ampla reorganização da nossa compreensão do presente, uma vez que o trabalho com Big Data permite a análise de séries longas de fatos remontando a séculos atrás. 


\section{Obser \\ ISSN n² 2447-4266 \\ Vol. 3, n. 4, Agosto. 2017 \\ DOI: http://dx.doi.org/10.20873/uft.2447-4266.2017v3n5p74}

Contudo, não há unanimidade sobre isso. Entendendo que a cultura histórica digital é parte de uma cultura digital mais vasta Noiret (2015) pontua que o uso de protocolos abertos favoreceu a troca de dados entre diferentes campos disciplinares, lastreando a criação de projetos colaborativos entre diversos pesquisadores. No entanto, sustenta que História Digital e Humanidades Digitais não são o mesmo. Na atualidade, todas as etapas do trabalho do historiador produção, divulgação e ensino contam com o uso do computador e se organizam em rede. No entanto, poucos são os pesquisadores que travam embates epistemológicos suscitados pelos meios digitais e menos ainda os capazes de produzir programas capazes de analisar ou criar novas formas de interação com as fontes. Com efeito, o gerenciamento das tecnologias digitais traz inúmeras dificuldades objetivas e poucos historiadores estão aptos a dominá-las. De fato, a prática da História Digital impõe a dupla exigência da reescrita dos métodos tradicionais e o domínio de novas práticas digitalizadas. Além disso, se a História Digital criou novos modos de trabalho com os documentos, assim como diferentes formas de acesso, armazenamento e tratamento, ainda há pouca reflexão sobre o uso crítico desses instrumentos de modo que há uma tarefa de primeira ordem, a saber, o desenvolvimento de uma discussão sobre o uso sistemático dessas ferramentas. 


\section{Obser \\ ISSN n² 2447-4266 \\ Vol. 3, n. 4, Agosto. 2017 \\ DOI: http://dx.doi.org/10.20873/uft.2447-4266.2017v3n5p74}

\section{Algumas questões metodológicas}

Uma interessante discussão sobre questões metodológicas inerentes ao campo das Humanidades Digitais pode ser encontrada no texto de Röhle e Rieder (2012), trabalho que tem relação com a conferência Digital Methods: Five Challenges: The Computational Turn" Conference, ministrada pelos autores em março de 2010, na Swansea University. Os autores partem da compreensão de que o uso dos computadores disseminou-se na sociedade pós-industrial. Além do acesso aos microcomputadores pessoais, ocorreu uma explosão de material disponível em formato digital. Nesse sentido, é possível estudar objetos não-digitais com a ajuda de computadores (livros, filmes), como também pesquisar objetos digitais, a exemplo de softwares, publicações online, jogos de computador, além da própria produção cultural e a interação social criadas através da mediação das máquinas. É esse contexto,caracterizado por uma produção crescente de dados, que leva os pesquisadores a buscarem métodos automatizados para viabilizarem suas análises. Pesquisas realizadas na Universidade de London, Tampere e Coimbra são citadas como exemplos de uso do computador na pesquisa de objetos não digitais. No primeiro caso, ferramentas de análise textual são usadas para identificar e classificar estruturas narrativas em roteiros cinematográficos. No segundo caso, trata-se de um sistema de recuperação de imagens aplicado a coleções de multimídia. No caso da Universidade de Coimbra, as tecnologias digitais são utilizadas para a análise de estratificações sociais em Portugal nos séculos XVII e XVIII. Já no caso da análise de objetos digitais, um exemplo é a pesquisa 


\section{Obser \\ ISSN n² 2447-4266 \\ Vol. 3, n. 4, Agosto. 2017 \\ DOI: http://dx.doi.org/10.20873/uft.2447-4266.2017v3n5p74}

baseada em software em redes sociais e outros espaços da internet, caracterizados pelo imenso volume de dados.

Um ponto importante sublinhado por Röhle e Rieder (2012) é a distinção do uso auxiliar e heurístico do computador por parte dos pesquisadores. A maioria deles faz uso do computador enquanto ferramenta auxiliar, com a função de organizar ou comunicar informações. Essas funções não são heurísticas, no sentido de contribuírem para a produção de um conhecimento novo. A opção pela produtividade heurística é importante por criar bases para compartilhar e comparar as pesquisas, fazer reivindicações de verdade e assim fazer avançar o conhecimento. Os autores sustentam que as tecnologias digitais podem oferecer uma contribuição heurística, no sentido de alterar o modo como os estudiosos veem, trabalham e interagem com seus materiais de pesquisa. A sua contribuição se dá, sobretudo, na descoberta de padrões e dinâmicas nos relacionamentos dos dados, explicitando propriedades que revelam aspetos particulares dos fenômenos estudados. No entanto, os autores consideram que é necessário uma maior discussão sobre o estatuto metodológico e epistemológico dessa operação, no sentido de pensar como esses métodos afetarão o modo como geramos e legitimamos o conhecimento nas Ciências Humanas. Também é preciso entender que conhecimentos e técnicas são necessários para nos servirmos deles.

Sustentam que uma boa posição é evitar extremos como um entusiasmo tecnológico ingênuo ou um medo paralisante, sendo necessário adotar uma postura reflexiva e construir uma relação 


\section{Observ}

ISSN n² 2447-4266

Vol. 3, n. 4, Agosto. 2017

DOI: http://dx.doi.org/10.20873/uft.2447-4266.2017v3n5p74

positiva entre processamento de dados e compreensão frutífera. Um primeiro desafio é evitar reproduzir uma noção de objetividade mecânica ou automática, no sentido de acreditar que o uso de ferramentas digitais poderia oferecer às Ciências Humanas uma objetividade positivista, no sentido de ter sido purgadas de elementos subjetivos. Porém o uso dos computadores pode ser eficaz para contornar obstáculos suscitado pelo campo de pesquisa. Contudo o uso dos computadores implica na adição de um componente complexo, a saber modos específicos de formalização, mais precisamente o uso dos algoritmos e formas bastante específicas de apresentação dos resultados, a exemplo de topologias de rede, cronogramas e cartografias visuais. Os autores advertem que é necessário evitar a sedução retóricas dessas imagens. Do ponto de vista metodológico é preciso à lógica utilizada na produção dessas imagens no sentido de compreender como essa representação visual pode promover um redimensionamento de um dado fenômeno. É preciso pôr em discussão o estatuto epistemológico das imagens, pois um argumento visual é muito mais difícil de ser contestado do que um argumento textual. Desse modo, é preciso pôr a nu os mecanismos de produção dessas imagens.

A proposta de Röhle e Rieder (2012), vai no sentido de que os pesquisadores possam objetivar e tornar transparente o processo de formalização de conteúdos e práticas em estruturas de dados, formas de representação e algoritmos. A transparência equivale à compreensão do método, suas premissas e funcionamento. Isso implica na possibilidade do pesquisador acessar o código fonte das 


\section{Obser \\ ISSN n² 2447-4266 \\ Vol. 3, n. 4, Agosto. 2017 \\ DOI: http://dx.doi.org/10.20873/uft.2447-4266.2017v3n5p74}

ferramentas que usa e, desse modo, compreender as ações que é levado a praticar. No limite, a obtenção da transparência indica que o pesquisador precisa entender a linguagem formal dos computadores.

\section{Considerações Finais}

O desenvolvimento das tecnologias digitais e a consequente produção de uma cultura digital impactaram diretamente na produção e circulação do conhecimento científico. A constituição de abordagens como a Sociologia, a Antropologia, a História Digital, enfim, o próprio campo das Humanidades Digitais é uma tentativa de reposicionar os pesquisadores em relação a esse giro digital. Apesar das inúmeras polêmicas no interior de cada um desses campos, a exemplo da divergência sobre a própria definição do "digital", os pesquisadores em geral concordam nas necessidades de promover discussões metodológicas e epistemológicas mais aprofundadas. Um ponto importante a destacar é a necessidade dos pesquisadores das Ciências Sociais e Historiografia adquirirem a competência nas linguagens que constituem as ferramentas digitais que utilizam em suas pesquisas, de modo a dar visibilidade aos seus pressupostos metodológicos.

\section{Referências}

ALMEIDA, Marco Antônio de. Humanidades digitais: um campo praxiológico para mediações e políticas culturais? XVI Encontro Nacional de Pesquisa em Ciência da Informação (XVI ENANCIB). João

Pessoa, 2015. Disponível

em: 


\section{Observotór \\ DOI: http://dx.doi.org/10.20873/uft.2447-4266.2017v3n5p74}

http://www.ufpb.br/evento/lti/ocs/index.php/enancib2015/enancib2 015/paper/viewFile/2999/1046.

BERRY, Michael J. A. e Linoff, G. Data Mining techniques. Wiley Computer Publishing, 1997.

CONTE, R. et al. Mediações - Revista de Ciências Sociais, $n^{\circ} 18$, vo.1, 2013, pp. 20-54.

DANNIAU, Fien. Public History in a Digital Context:Back to the Future or Back to Basics. Low Countries Historical Review, vol. 128-4, 2013, pp. 118-144.

DORN, Sherman. Is (Digital) History More thananArgumentaboutthePast?In: NAWROTZKI, Kristen; DOUGHERTY, Jack. Writing History in the Digital Age. Michigan: University of Michigan Press, 2013, pp.21-34.

FAYYAD, U.; PIATETSKY-SHAPIRO, G.; SMYTH, P. From data mining toknowledgediscovery: an overview. In.: FAYYAD, U.; PIATETSKYHAPIRO, G.; SMYTH, P.; UTHURUSAMY, R., Eds., Advances in knowledge discovery. Cambridge: MIT Press, 1996, pp. 1-36.

GOEBEL, M.; GRUENWALD, L. A survey of data mining and knowlodge Discovery software tools. SIGKDD Explorations, v. 1, pp. 20-33, 1999.

GIBBS ,Fred;OWENS, Trevor. The Hermeneutics of Data and Historical Writing. In.: NAWROTZKI, Kristen; DOUGHERTY, Jack. Writing History in the Digital Age. Michigan: University of Michigan Press, 2013, p. 159-170.

LUPTON, D. Digital Sociology. Routledge, 2015.

SEGATA, Jean. A etnografia como promessa e o "efeito-Latour" no campo da cibercultura. Itha - Revista de Antropologia. Florianópolis, v. 16, n. 1, 2015a. p. 69-95.

MÁXIMO, Maria Elisa. Da metrópole, às redes sociotécnicas: a caminho de uma antropologia no ciberespaço. In. RIFIOTIS, Theophilos (Org.). Antropologia no ciberespaço. Santa Catarina, Editora UFSC, 2010, pp.29-44. 


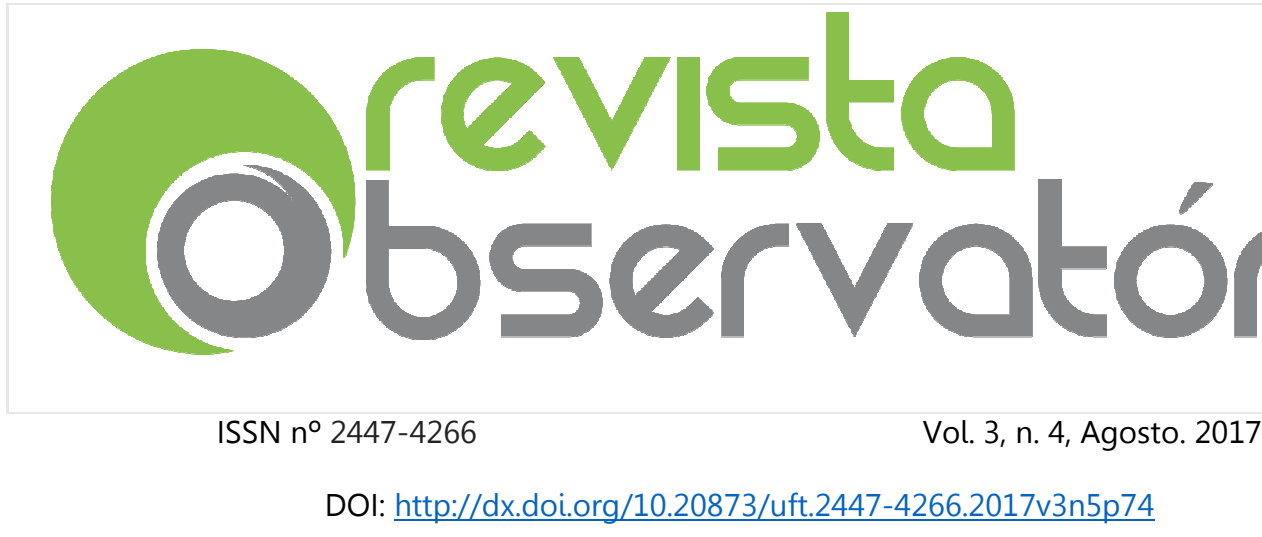

MILLER, Daniel; HORST, Heather A. O Digital e o Humano: prospecto para uma Antropologia Digital. Parágrafo, v. 2, n. 3 jul./dez.2015, pp.91-111.

NASCIMENTO, L. A Sociologia Digital: um desafio para o século XXI. Sociologias, Porto Alegre, ano 18, $n^{\circ} 41$, jan/abr 2016, p. 216-241.

NOIRET, S. História Pública Digital | Digital Public History. Liinc em Revista, v. 11, n. 1, 2015. Disponível em: <http://liinc.revista.ibict.br/index.php/liinc/article/view/797/528>. Acesso em: 28/7/2016.

PEREIRA, Paulo Silva. Academia, Geopolítica das Humanidades Digitais e Pensamento Crítico. MATLIT: Materialidades da Literatura, v. 3, n. 1, p.111-140, out. 2015. Disponível em: $<$ http://iduc.uc.pt/index.php/matlit/article/view/2517/1687>.

RÖHLE \& RIEDER. Digital methods: Five challenges. In.: BERRY, D. M. (Org.). Understanding Digital Humanities. London: Palgrave Macmillan UK, 2012.

TANAKA, Stefan. Pasts in a Digital Age. In.: NAWROTZKI, Kristen; DOUGHERTY, Jack. Writing History in the Digital Age. Michigan: University of Michigan Press, 2013, pp. 35-46.

ZAAGSMABMGN, Gerben. On Digital History. Low Countries Historical Review, vol. 128-4, 2013, pp. 3-29.

ZAHAVI, Gerald. Notes fromthe Field: Digital Historyand Oral History.In: BOYD Douglas A.; LARSON, Mary A. Oral History and Digital Humanities: Voice, Access, and Engagement. New York: Palgrave Macmillan, 2014, p.119-131. 